\title{
Landsat-8 On-orbit and Landsat-9 Pre-launch Sensor Radiometric Characterization
}

\author{
Brian Markhama, Julia Barsib, Matthew Montanaroc, Joel McCorkela, \\ Aaron Gerace ${ }^{c}$, Jeffrey Pedeltya ${ }^{a}$ Simon Hook ${ }^{d}$, Nina Raquenoc, \\ Cody Andersone, and Md Obaidul Haque ${ }^{f}$
}

a NASA/Goddard Space Flight Ctr., Greenbelt, MD, USA 20771; b Science Systems and Applications, Inc, NASA/Goddard Space Flight Ctr., Greenbelt, MD, USA 20771; ' Rochester Institute of Technology, Rochester, NY 14623; 'NASA/Jet Propulsion Lab., Pasadena, CA, 91109;

e United States Geological Survey/Earth Resources Observation and Science, Sioux Falls, SD 57198,

f Stinger Ghaffarian Technologies, Inc, Contractor to United States Geological Survey (USGS) 


\section{Landsat Team}

The Landsat program, with the Landsat- 7 and Landsat- 8 satellites in orbit and the Landsat-9 observatory (instruments and spacecraft) under development, is a joint NASA and United States Geological Survey (USGS) effort.

The Landsat- 8 and -9 OLI (2) instruments were built and are being built by Ball Aerospace (Leanne Presley, current project manager; Ed Knight, lead system engineer and Geir Kvaran, radiometric calibration lead) under contract to NASA. The TIRS and TIRS-2 instrument are in-house NASA/GSFC builds (Jason Hair, current project manager; Synthia Tonn, lead systems engineer; Dennis Reuter, instrument scientist).

The overall project is led by Del Jenstrom at NASA and Brian Sauer at USGS. The NASA project scientist is Jeff Masek; the NASA instrument scientist is Phil Dabney; the USGS project scientist is John Dwyer.

The Cal/Val team also includes a number of NASA and USGS contractors as well as personnel from RIT, South Dakota State University, University of Arizona. 


\section{Topics}

- Landsat 8, 9 Instrument Overview

- Operational Land Imager (OLI)

- Thermal Infrared Sensor (TIRS)

- Landsat-8 Instrument Status and On-orbit Radiometric Performance Characterization

- Landsat-9 Instrument Status and Pre-launch Radiometric Performance Characterization 


\section{Instrument Overview (1)}

LANDSAT-8

USGS - NASA

- Two sensors on both missions:

- Operational Land Imager - reflective sensor with 9 bands

- Thermal Infrared Sensor - thermal sensor with 2 bands

\begin{tabular}{|c|c|c|c|c|}
\hline Band & Band Designation & $\begin{array}{c}\text { Landsat-8 Band } \\
\text { Edges }(\mathrm{nm})\end{array}$ & GIFOV (m) & $\begin{array}{c}\text { Digitization } \\
\text { (transmitted } \\
\text { bits) }\end{array}$ \\
\hline 1 & Coastal Aerosol & $435.0-451.0$ & 30 & $12^{*}$ \\
\hline $\mathbf{2}$ & Blue & $452.0-512.1$ & 30 & $12^{*}$ \\
\hline $\mathbf{3}$ & Green & $532.7-590.1$ & 30 & $12^{*}$ \\
\hline 4 & Red & $635.9-673.3$ & 30 & $12^{*}$ \\
\hline $\mathbf{5}$ & NIR & $850.5-878.8$ & 30 & $12^{*}$ \\
\hline $\mathbf{6}$ & SWIR-1 & $1566.5-1651.2$ & 30 & $12^{*}$ \\
\hline $\mathbf{7}$ & SWIR-2 & $2107.4-2294.1$ & 30 & $12^{*}$ \\
\hline $\mathbf{8}$ & Pan & $503.3-675.7$ & 15 & $12^{*}$ \\
\hline $\mathbf{9}$ & Cirrus & $1363.2-1383.6$ & 30 & $12^{*}$ \\
\hline 10 & TIR-1 & $10602-11190$ & 100 & 12 \\
\hline 11 & TIR-2 & $11500-12511$ & 100 & 12 \\
\hline
\end{tabular}

* 14 bits on Landsat-9 


\section{Instrument Overview (2)}
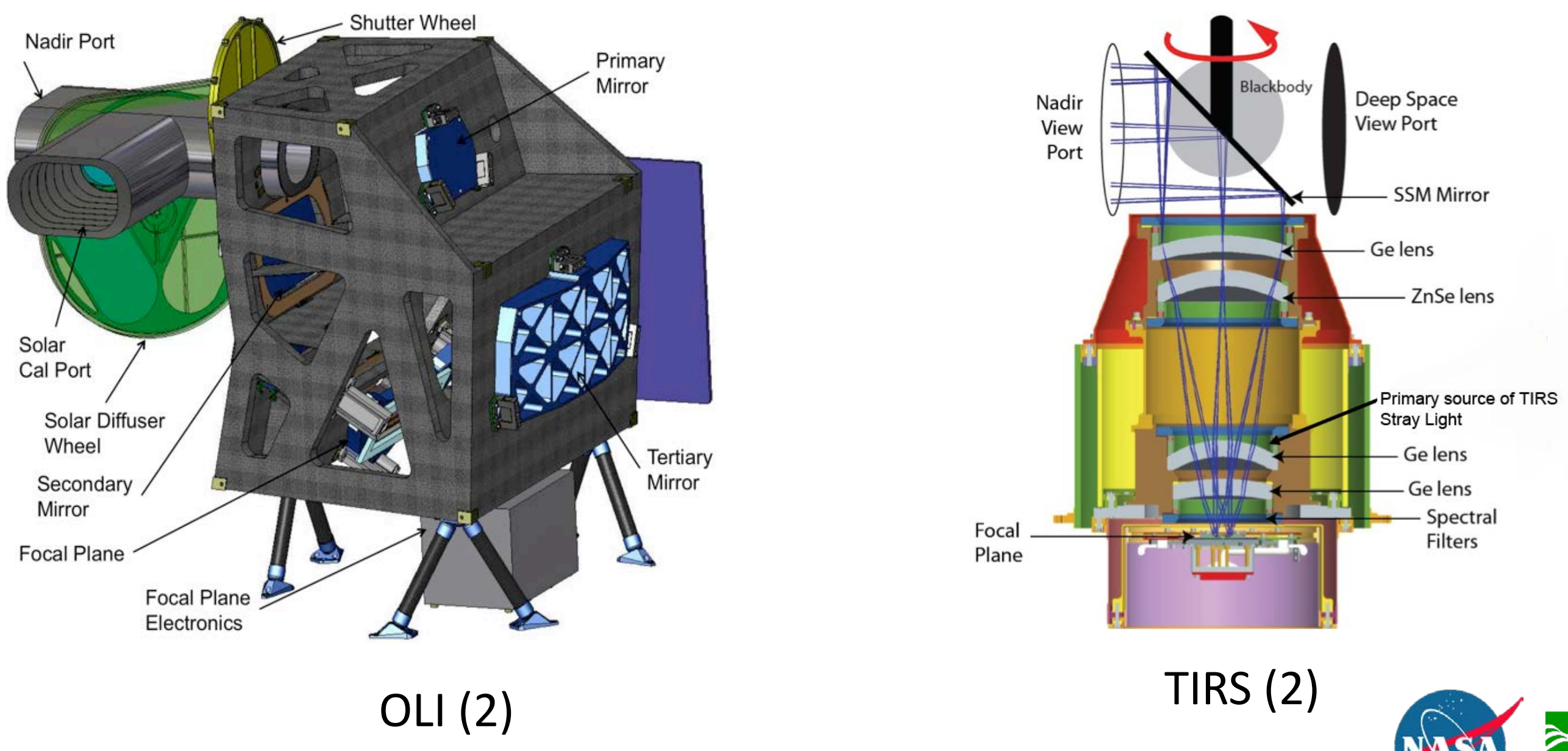

TIRS (2) 


\section{Instrument Overview (3)}
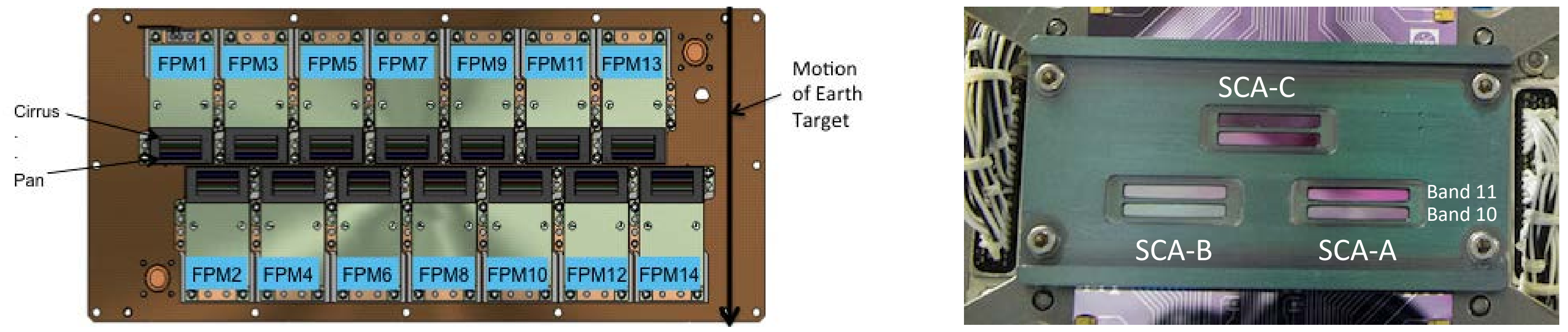

OLI (2) Focal Plane

TIRS-2 Focal Plane 


\section{Landsat-8 OLI On-orbit Status and Radiometric Performance}

- Five and one-half years on-orbit, continuous operation on side $A$ electronics, $100 \%$ detector operability

- Radiometric performance monitoring with:

- Daily "working" stim lamps

- 1/16 day "backup" stim lamps

- 1/6 months "pristine" stim lamp

- Weekly "working" diffuser

- 1/6 months "pristine" diffuser

- 1/month lunar imaging

- Vicarious data collections, NTE 1/16 days, two sites (RRV and Brookings, SD) 


\section{Landsat-8 OLI Signal-to-Noise Ratio (SNR)}

- Median Detector in each band trended

- Tracked using daily darks and stim lamps and weekly diffusers (2 signal levels plus dark) modeled to provide SNR at "typical" radiance $\left(L_{\text {typ }}\right)$.

- Reported on quarterly basis

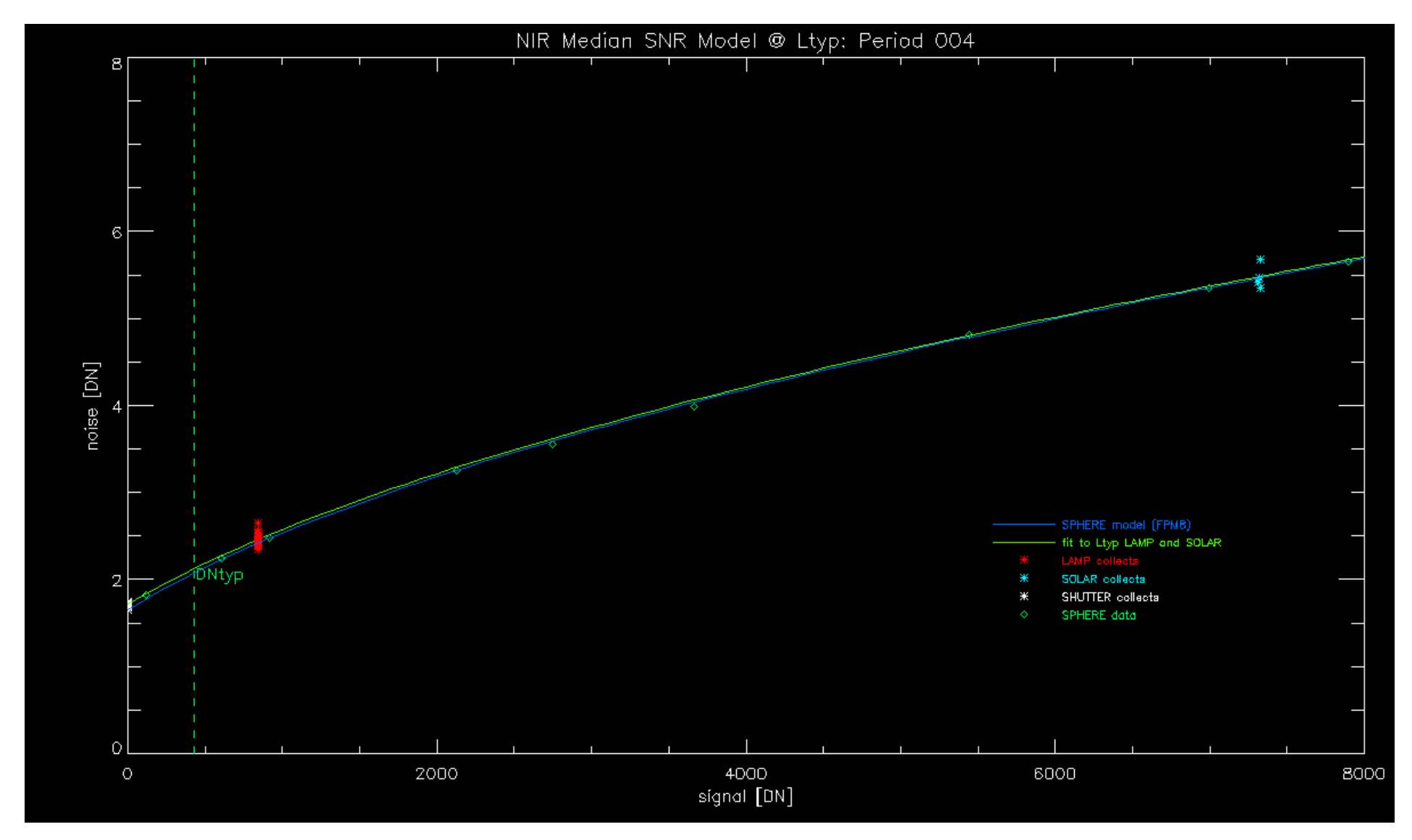




\section{Landsat-8 OLI Signal-to-Noise Ratio (SNR)}

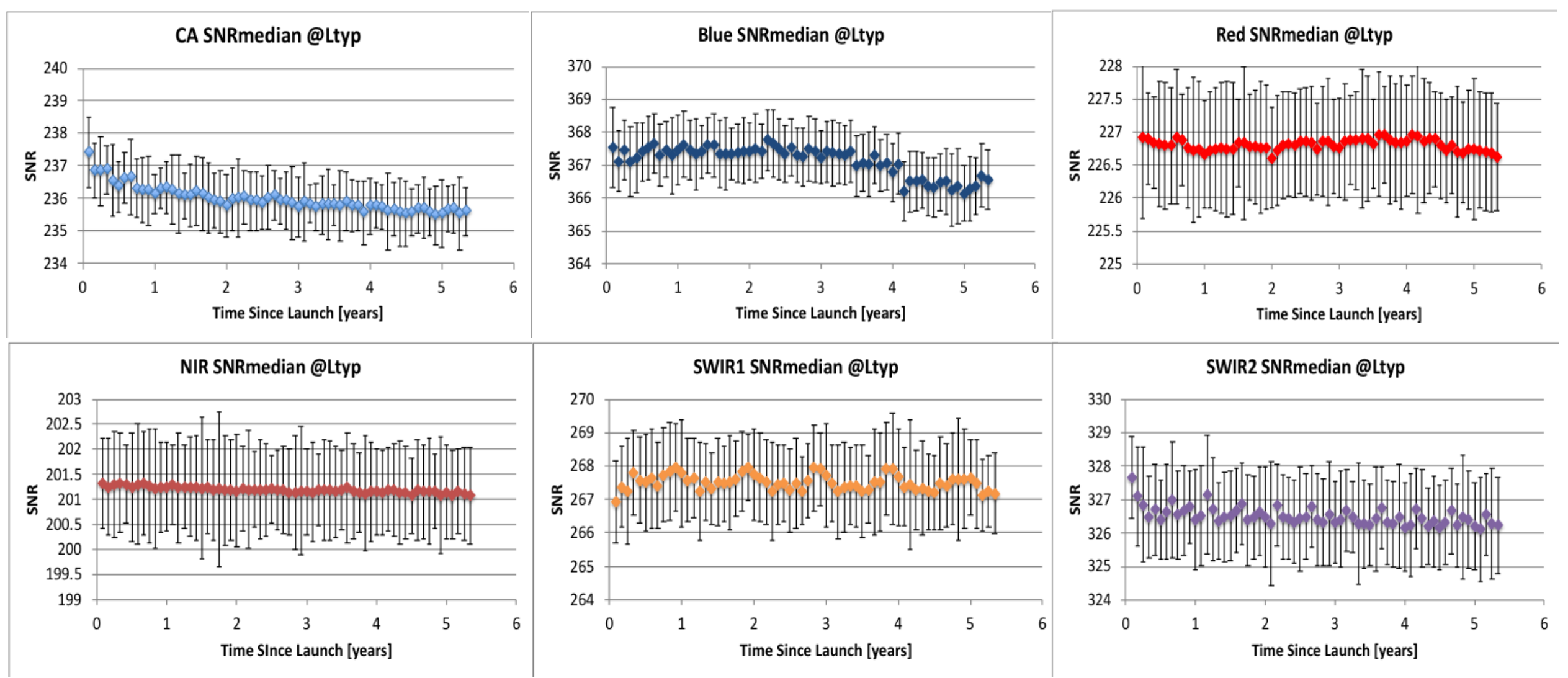




\section{Landsat-8 OLI Response Stability (1)}

- Band Average

- Monitored with all onaboard sources plus lunar views

- CA band (1) largest change, circa $1.3 \%$ over 5 plus years

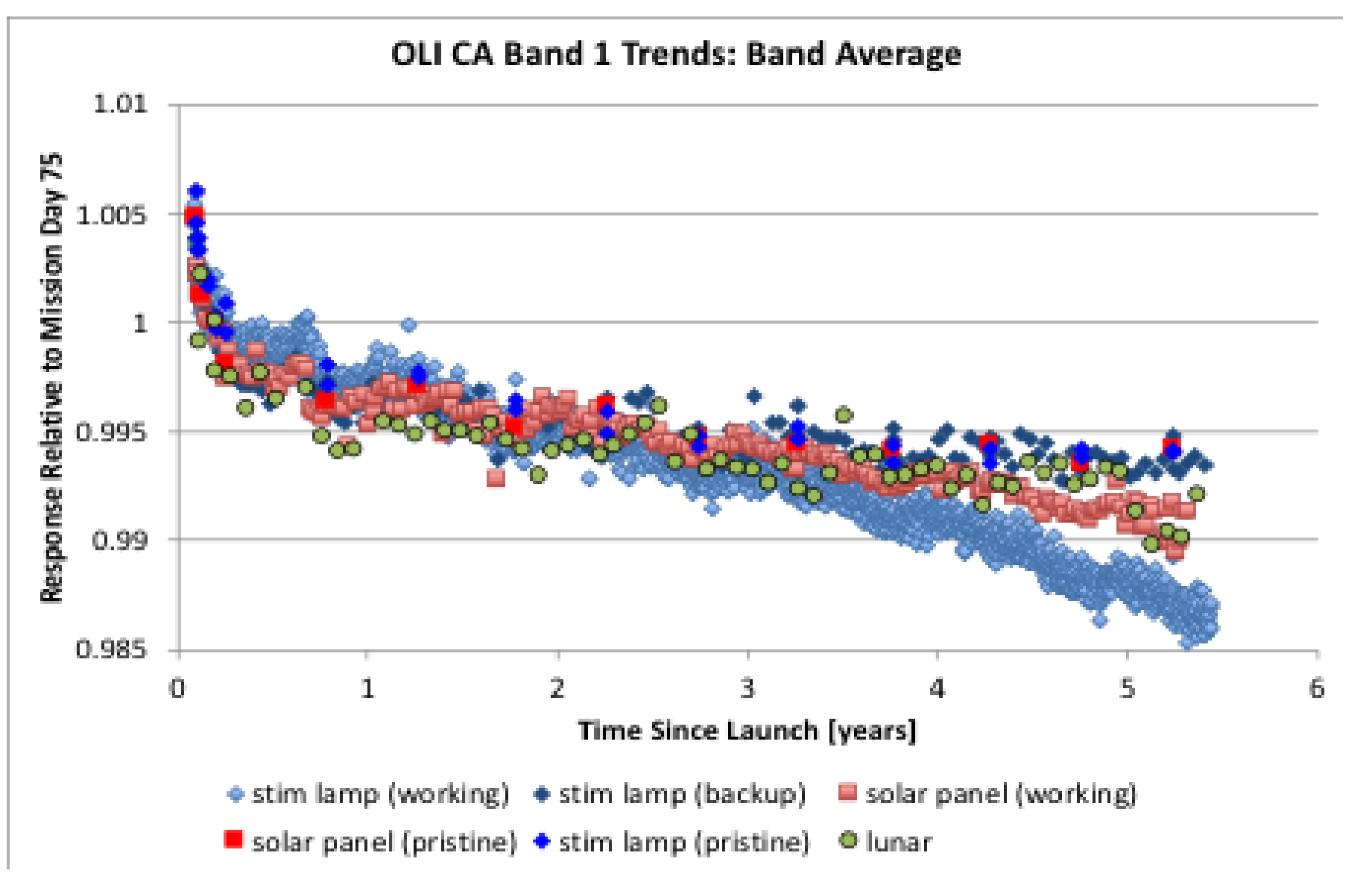


LANDSAT Landsat-8 OLI Response Stability (2)
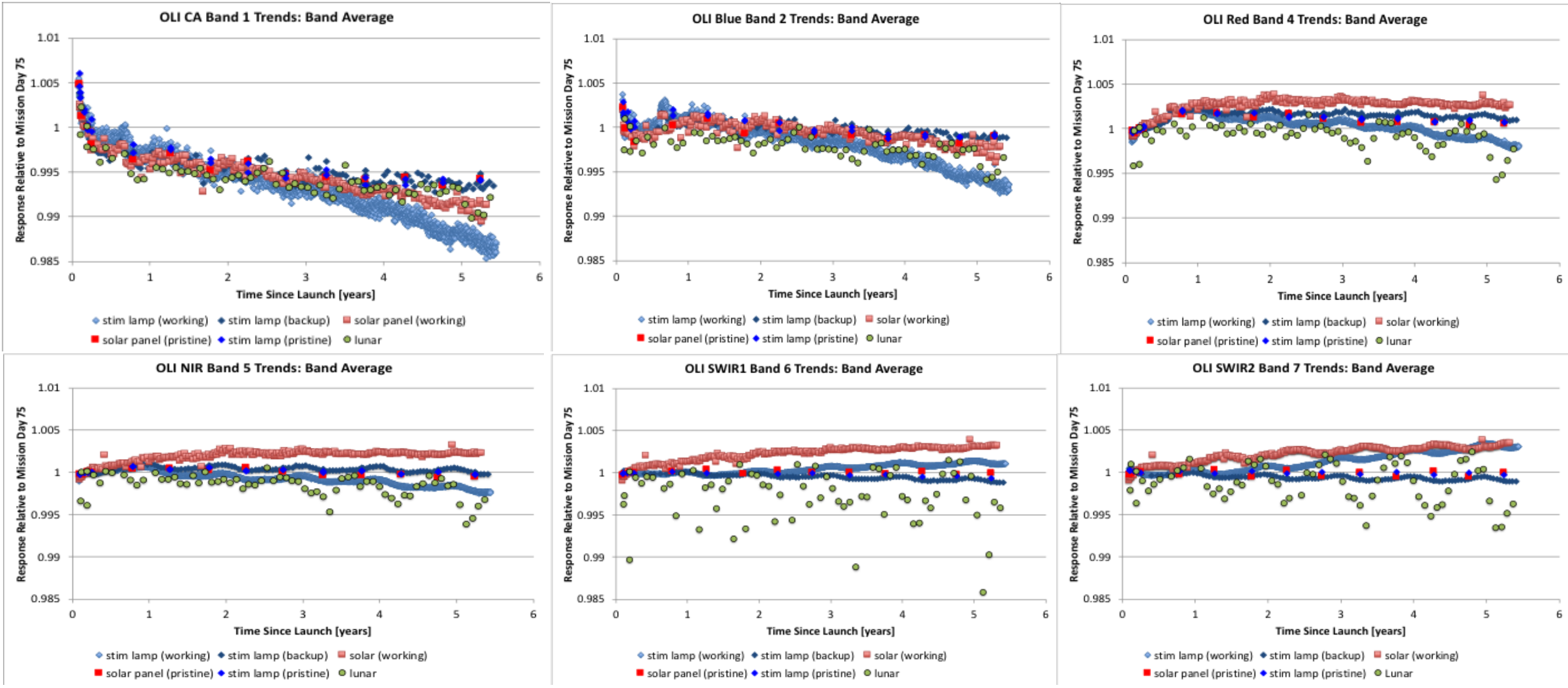
- All calibrators give comparable trends within $~ 0.5 \%$ over $5+$ years

- All bands stable to better than $1.5 \%$ over $5+$ years

- Some apparent degradation in most used calibrators

- Working stim lamps - color temperature like shift - decreased output in blue, increased output in SWIR (operated at constant current)

- Working diffuser - some decrease in blue, increase in longer wavelengths

- "Pristine" calibrators best behaved

- Lunar collects have most variability in SWIR - being reduced with revised lunar model. 
- Detector-to-Detector (striping)

or "relative gains"

- Using weekly diffusers- ratio responses to characterize changes

- Standard deviation of ratio quantifies changes

- VNIR (silicon) 0.01\%

- SWIR (HgCdTe) 0.03\%
Relative Gain Variability Between Consecutive Diffuser Acquisitions

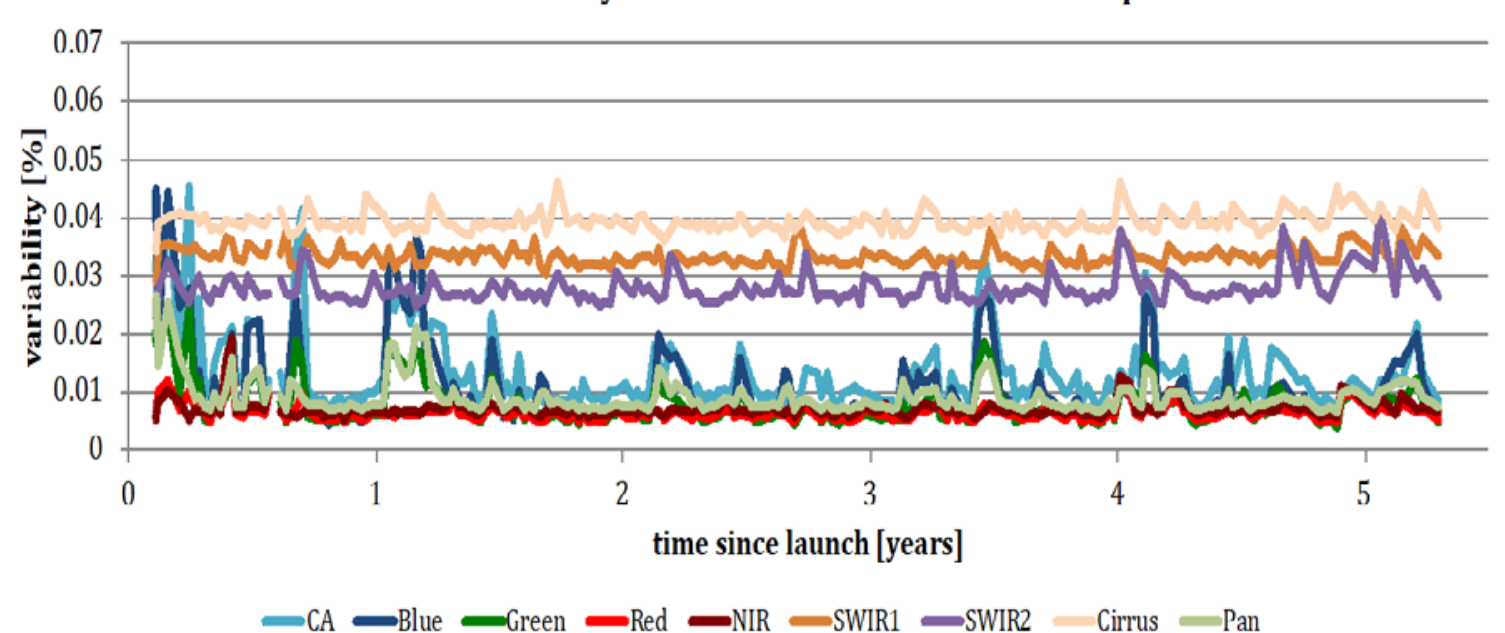




\section{LANDSAT Landsat-8 OLI Response Stability (5)}

- Some "jumpers" in SWIR

- Change by up to $1.5 \%$ "instantaneously"

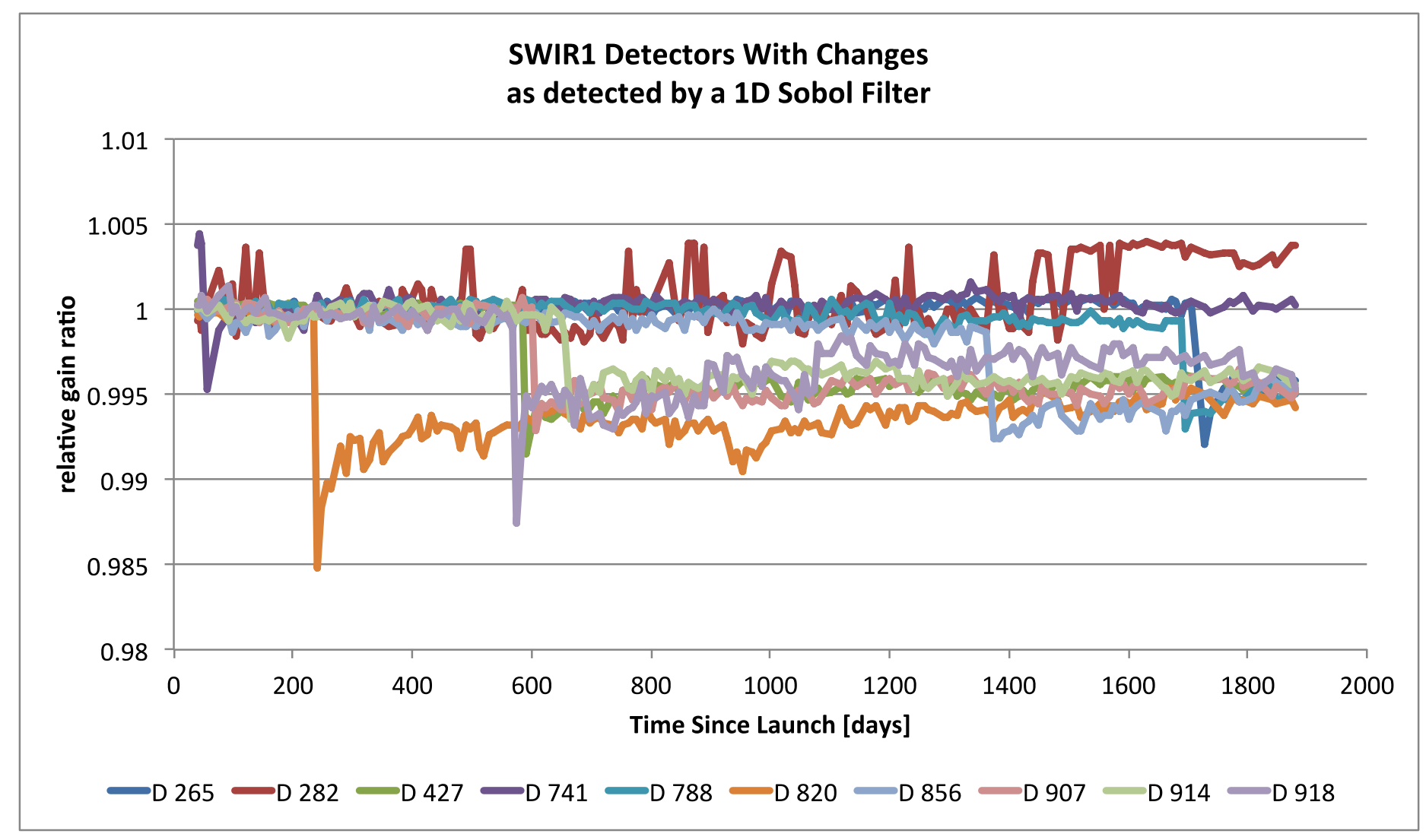




\section{S2A MSI and OLI \\ Lifetime Average Ratios Between \\ Coincident Acquisitions}

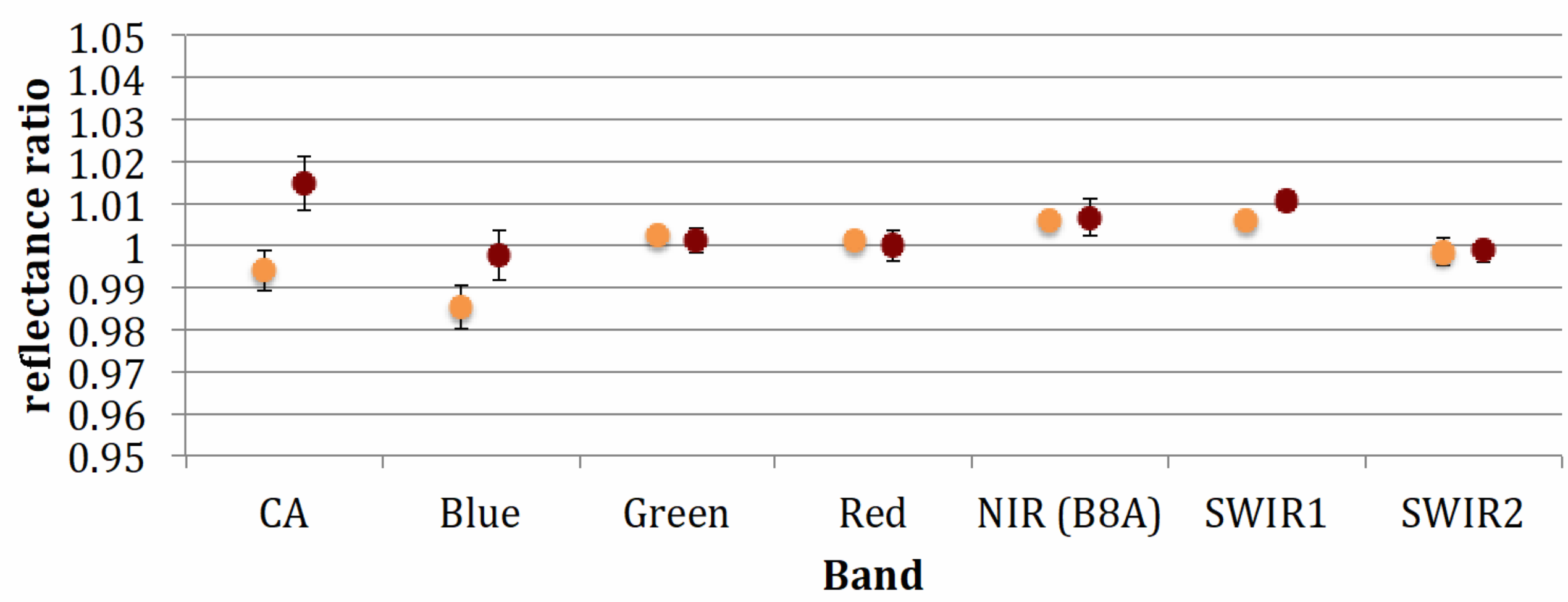

- Algeria-3 (n=9) - Libya-4 (n=8) 


\section{Landsat-8 TIRS On-orbit Status and Radiometric Performance}

- Five and one-half years on-orbit, $100 \%$ detector operability, Scene Select Mirror (SSM)encoder issues caused side-B switch and alternate operations concept

- SSM encoder turned on once/2 weeks

- Radiometric calibration 2 /month versus original 2 /orbit

- Radiometric performance monitoring with:

- Blackbody and Deep Space views (originally 2/orbit - now 2/month)

- Blackbody temperature variable from $270 \mathrm{~K}$ to $320 \mathrm{~K}$

- Vicarious data collections, two teams (JPL- Tahoe, Salton Sea, RIT- NOAA buoys) 


\section{Landsat-8 TIRS On-orbit Response Stability}

TIRS Responsivity Metric

as calculated from per-orbit calibration collects

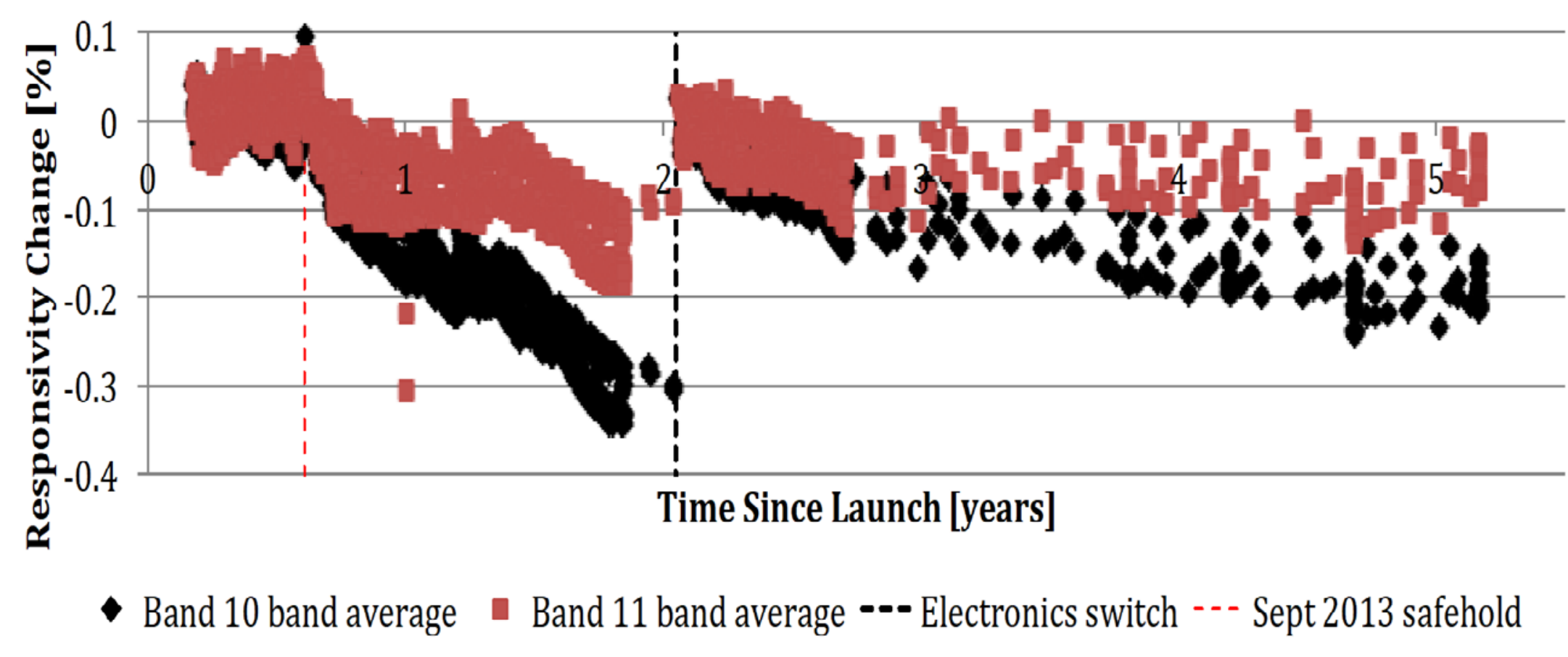




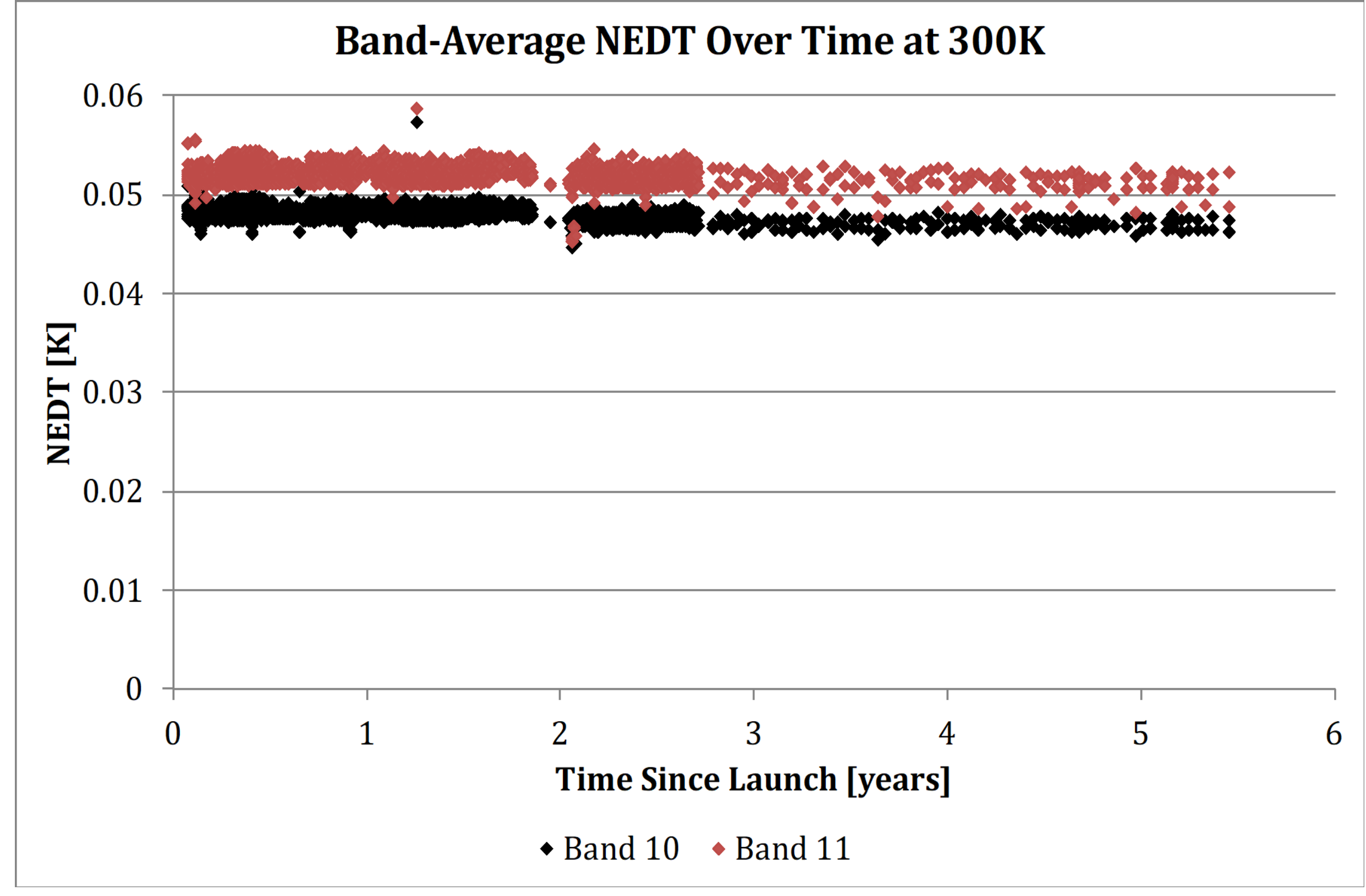




\section{Landsat-8 TIRS On-orbit Response Uniformity (1)}

Pre - Stray Light correction Post - Stray Light correction
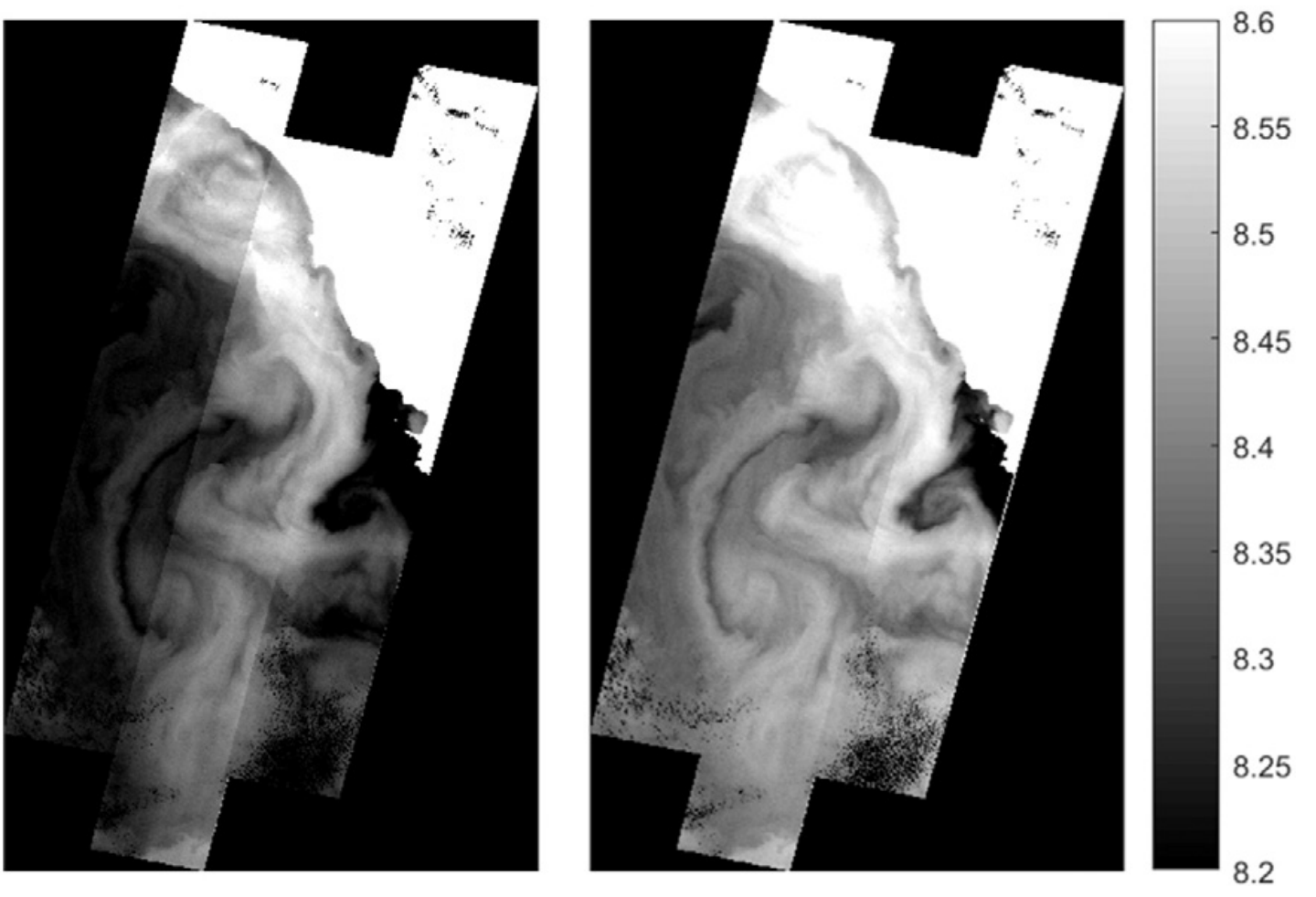

- Focal plane location dependent stray light produces image artifacts (striping, banding)

- Stray light algorithmic correction reduces artifacts 


\section{Landsat-8 TIRS On-orbit Response Uniformity (2)}

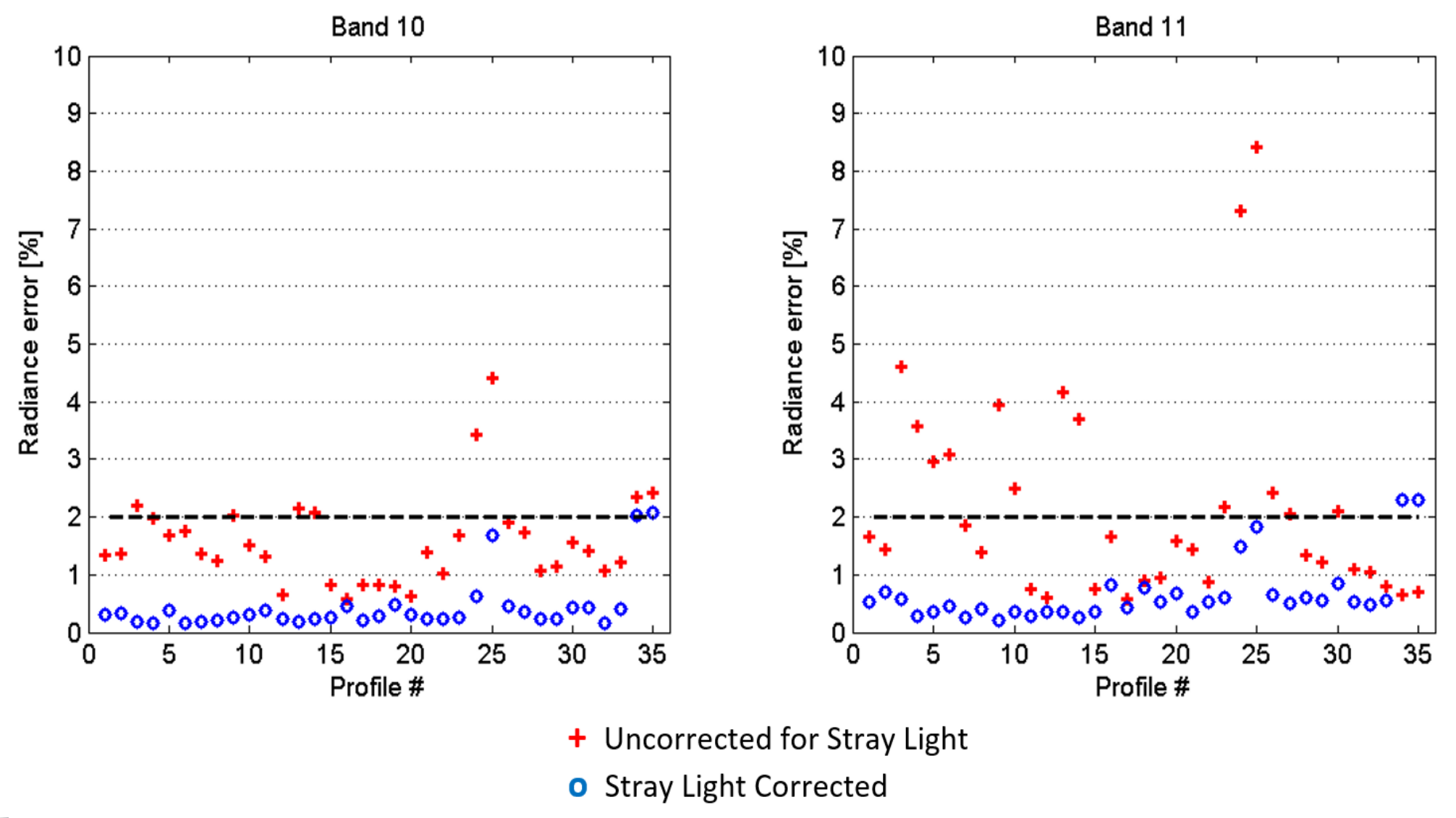

- Stray light algorithmic correction reduces RMS radiometric error (compared to MODIS [during commissioning] -20 minutes later)

- Few outlier points were land targets

- Stray Light Corrected 


\section{Landsat-8 TIRS On-orbit Calibration Uncertainty}

Comparison to surface buoy water temperature measurements and atmospheric propagation

\begin{tabular}{llrrrr}
$\begin{array}{l}\text { Daytime } \\
\text { Side-A }\end{array}$ & N & $\begin{array}{c}\text { Calibration Version 6 } \\
\text { Whole focal plane } \\
{[\mathrm{W} / \mathrm{m} 2 \mathrm{sr} \text { um] }}\end{array}$ & $\begin{array}{c}\text { Calibration Version 6 } \\
\text { Whole focal plane } \\
{[\mathrm{K}]}\end{array}$ & $\begin{array}{c}\text { Calibration } \\
\text { Version 6 RMSE } \\
{[\mathrm{K}]}\end{array}$ \\
\hline B10 & 141 & $-0.02+/-0.01$ & -0.15 & 0.47 \\
\hline B11 & 141 & $0.06+/-0.02$ & 0.53 & 0.53 \\
\hline $\begin{array}{l}\text { Daytime } \\
\text { Side-B }\end{array}$ & & & & & \\
\hline B10 & 275 & $-0.06+/-0.01$ & 0.43 & 0.42 \\
\hline B11 & 275 & $0.00+/-0.01$ & 0.00 & 0.74 \\
\hline
\end{tabular}

Small bias (probably correctable) and RMSE now comparable to previous Landsat thermal sensors 


\section{Landsat-9 OLI-2 Pre-Launch Status and Radiometric Performance}

- Nearly a carbon copy of Landsat-8 OLI

- Instrument fully integrated (minus baseplate, thermal hardware and flight diffusers)

- Recently completed spatial characterization (focus, edge response, ghosting, bright target recovery) thermal vacuum testing $(9 / 6 / 18)$

- Performance generally comparable to Landsat-8 OLI

- Preparing for spectral (new test set) and radiometric characterization (revised procedures) in thermal vacuum, starting $\sim$ mid-November 2018

- Current delivery to observatory integrator, late summer 2019

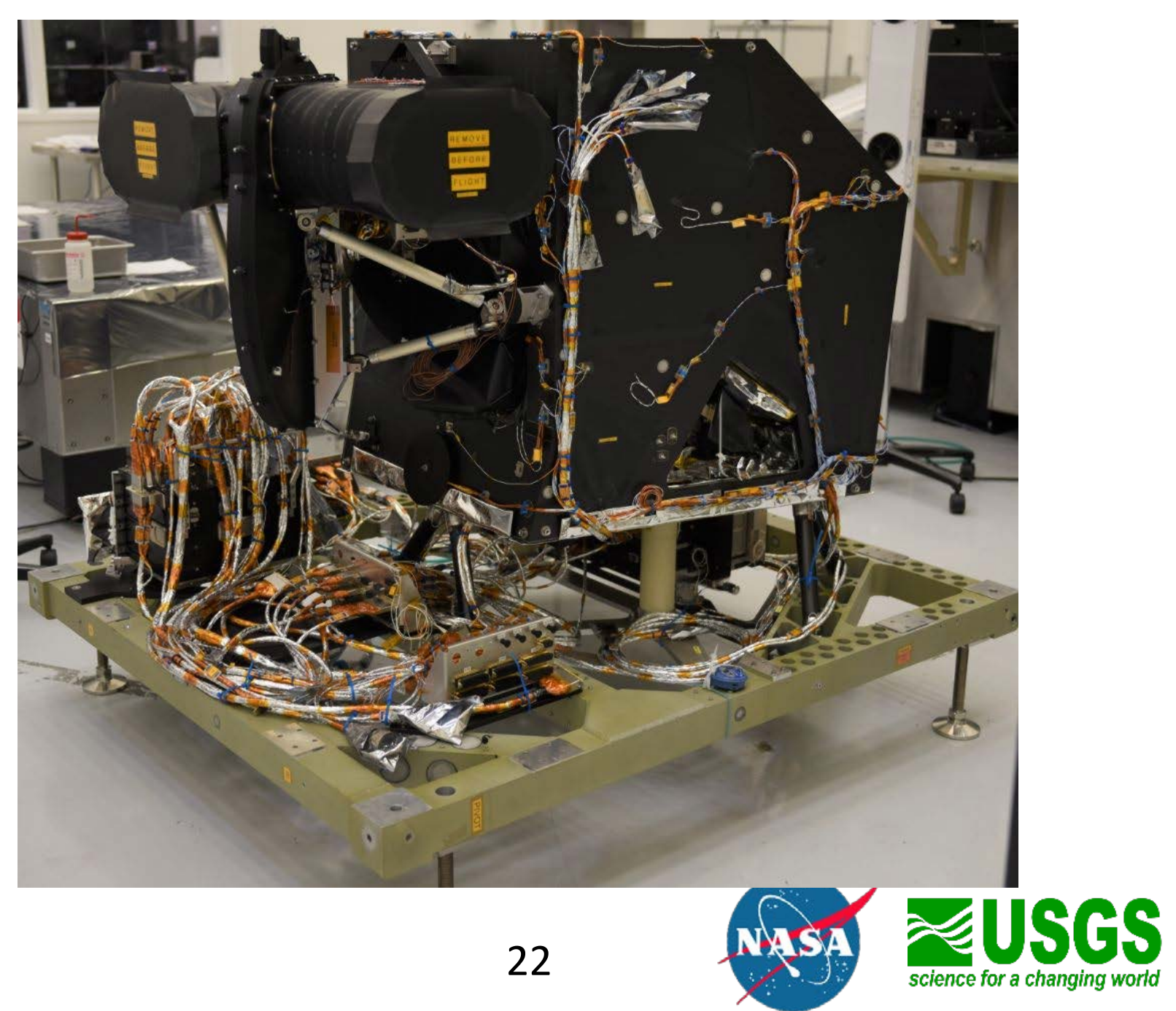


- Multiple tunable wavelength, narrow linewidth laser systems

- Provides complete coverage over earth-observing systems spectral range

- In-house built optical parametric oscillator (OPO) systems with two ring cavities each, for coverage 350-2200nm

- Tables referred to as OPO Laser Alignment Facilities (OLAFs)

- Two COTS systems, Argos and CLT, for coverage above 2200nm

- Illumination from lasers fed to sphere via fiber optic cables

- Three radiometers inside the sphere monitor the radiance from the laser

- Provide feedback to the power stabilizer on the OLAFs for radiance-stabilized signal

- Output of radiance from 30" integrating sphere viewed by instrument under test

- External transfer radiometers transfers NIST-traceable calibration to sphere monitor radiometers

- All tuning is computer controlled

- Allows for efficient scanning operation over large wavelength ranges

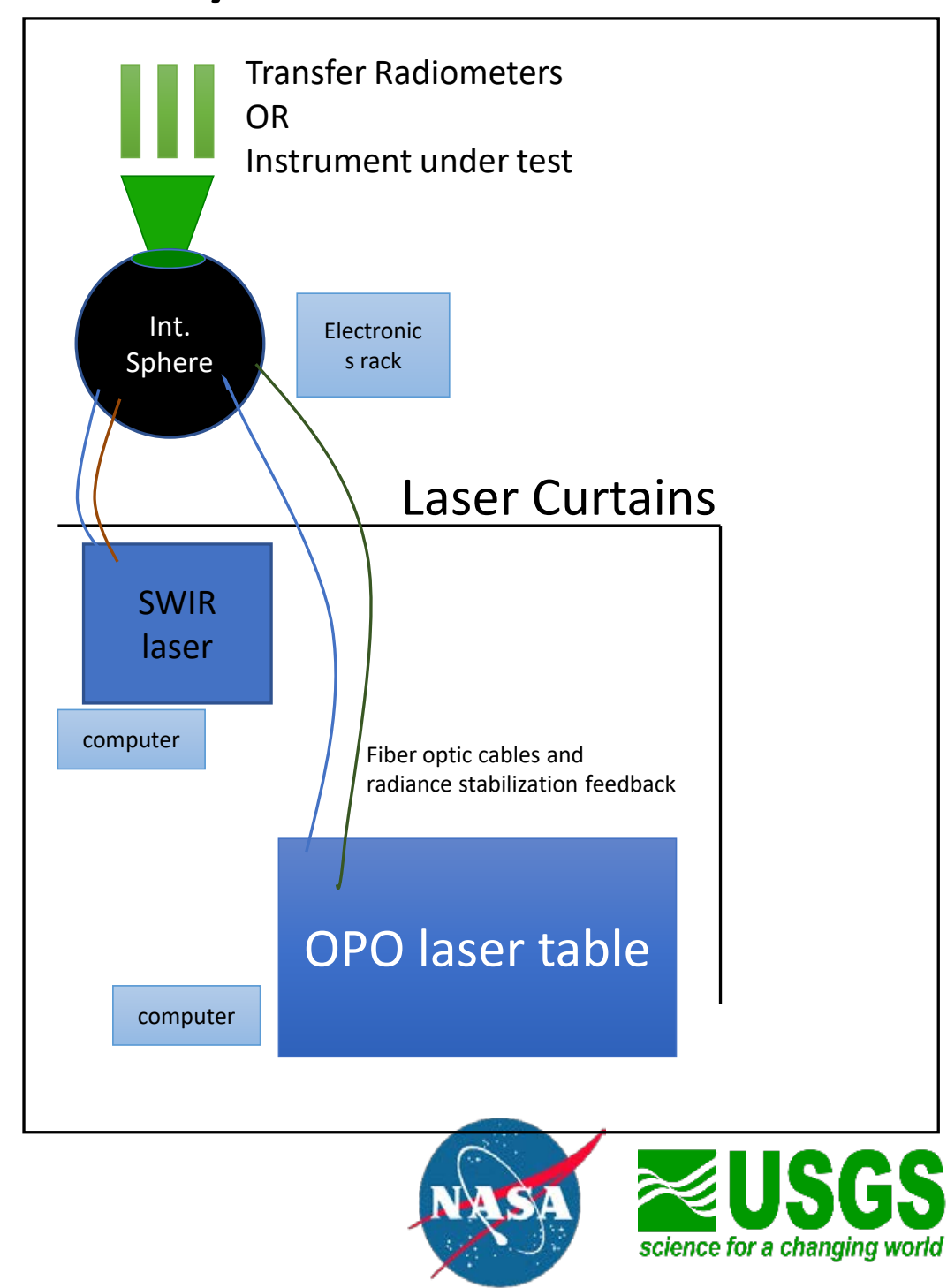




\section{GLAMR Integrating Sphere}

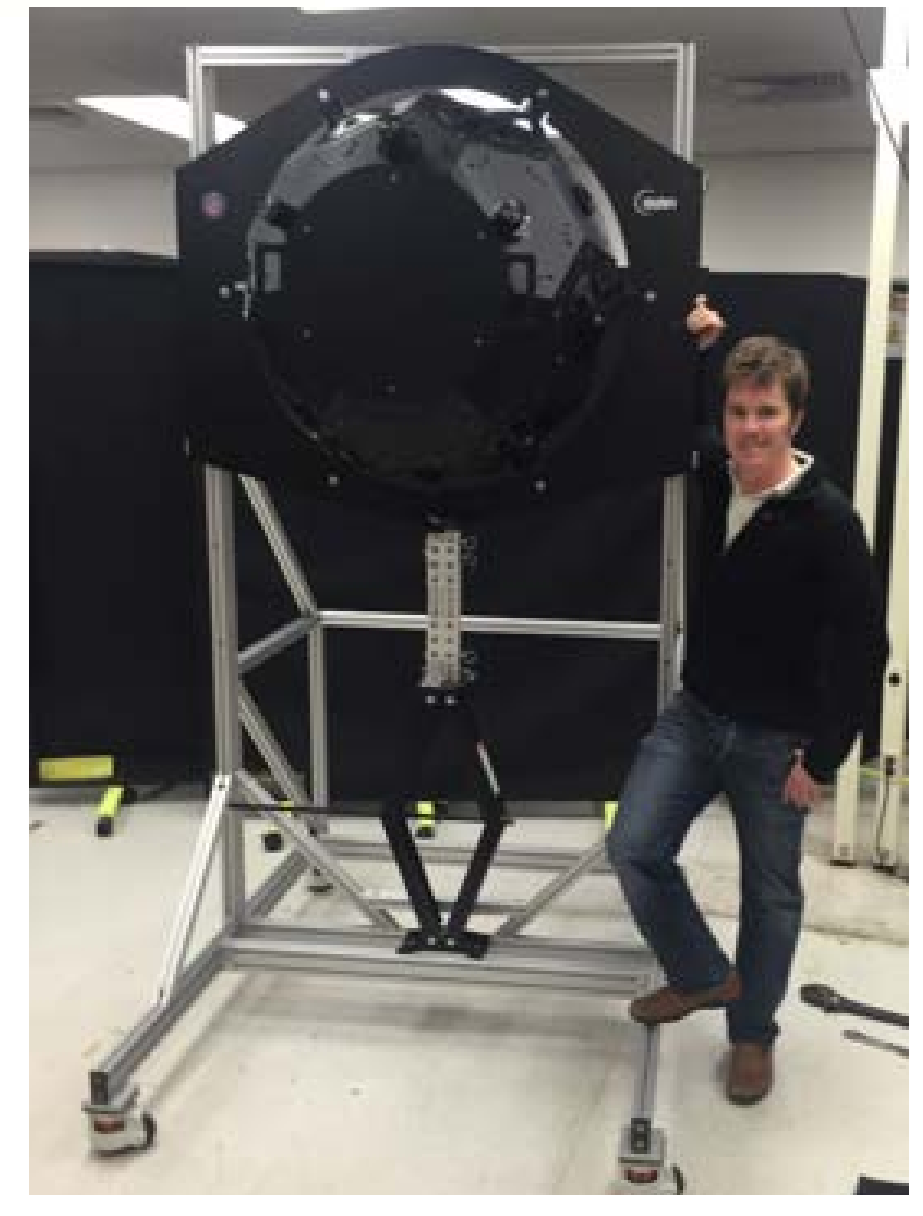

Sphere at approximately OLI-2 deployment height 


\section{GLAMR Spectral Coverage and OLI Spectral Response}

\section{GLAMR Coverage and OLI Bandpasses}

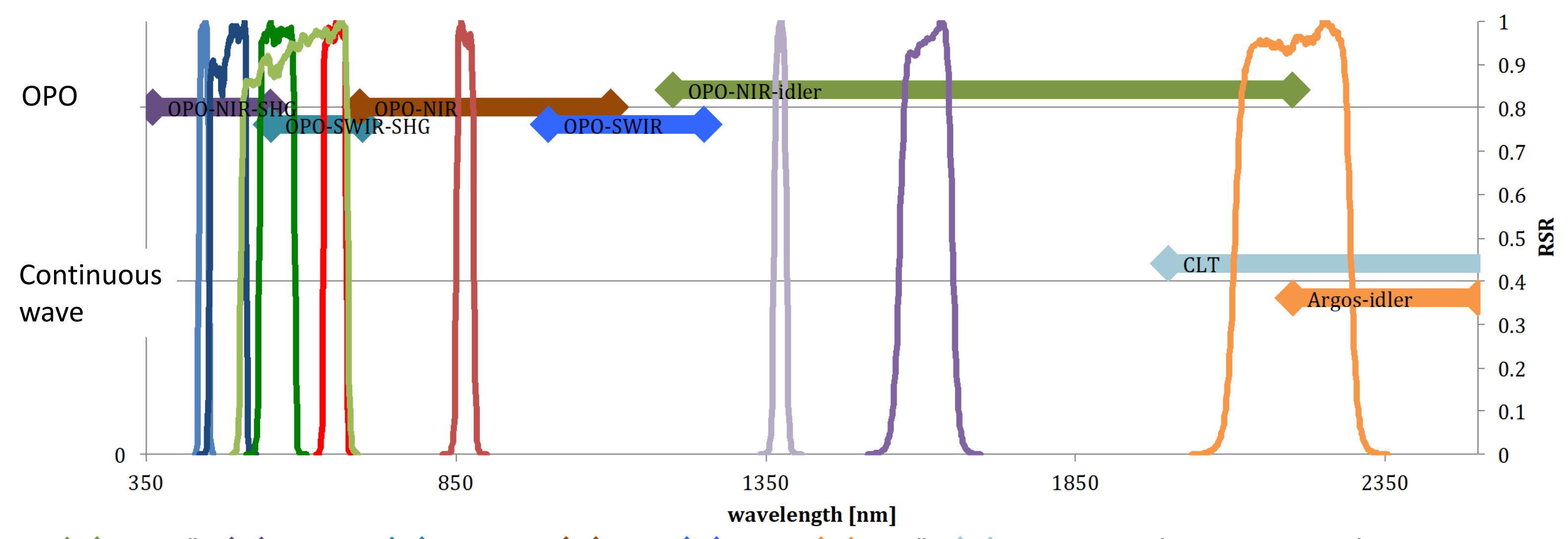

$\leadsto$ OPO-NIR-idler $\leadsto$ OPO-NIR-SHG $\leadsto$ OPO-SWIR-SHG $\leadsto$ OPO-NIR $\leadsto$ OPO-SWIR $\leadsto$ Argos-idler $\leadsto$ CLT $\longrightarrow$ CA $\longrightarrow$ Blue $\longrightarrow$ Green $\longrightarrow$ Red $\longrightarrow$ NIR $\longrightarrow$ Pan 


\section{Improvements to OLI-2 Spectral Characterization}

- Full focal plane characterization

- OLI monochromator-based test only illuminated about 60 detectors at a time

- 16 positions on the focal plane were tested ( 15\%)

- In-band and out-of-band characterization at instrument level

- For OLI, out-of-band response was characterized at the module level

- Larger field full aperture illumination

- All bands within a module illuminated as well as adjacent modules

- Within module and between adjacent module crosstalk effects now included

- NIST traceable radiance

- Can provide a check on the DSS absolute calibration 


\section{Landsat-9 TIRS -2 Pre-Launch Status and Radiometric Performance}

- Largely a copy of Landsat-8 TIRS

- Revised baffling for stray light control

- Revised SSM encoder design for reliability

- Increased redundancy for reliability

- Instrument fully integrated

- Completed stray light, spatial and spectral tests in partially integrated form (minus SSM and front baffles)

- Stray light reduced by about an order of magnitude

- Spectral and spatial (Not final test) performance generally comparable to Landsat-8 TIRS

- Spatial and spectral response better understood

- Two thermal vacuum performance tests planned (November 2018, February 2019)

- Current delivery to observatory integrator, late summer 2019

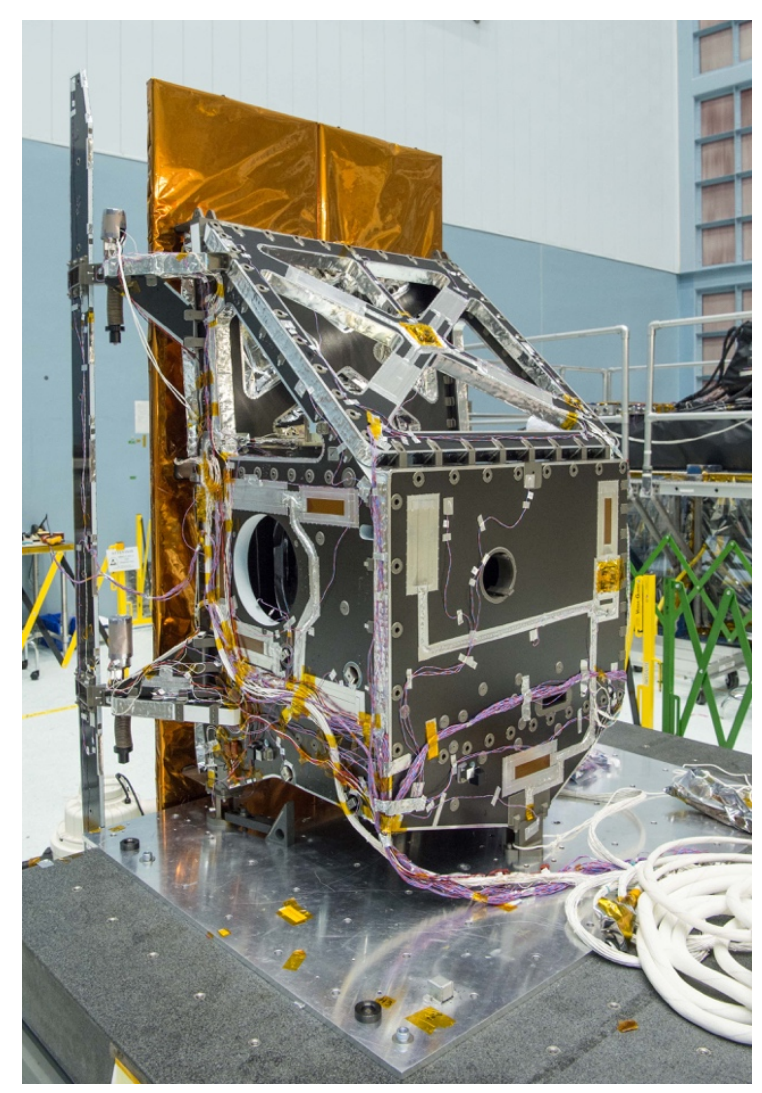




\section{Landsat-9 TIRS -2 Stray Light Performance (1)}

- Largely a copy of Landsat-8 TIRS

- Revised baffling for stray light control

- Revised SSM encoder design for reliability

- Increased redundancy for reliability

- Instrument fully integrated

- Completed stray light, spatial and spectral tests in partially integrated form (minus SSM and front baffles)

- Stray light reduced by about an order of magnitude

- Spectral and spatial (Not final test) performance generally comparable to Landsat-8 TIRS

- Spatial and spectral response better understood

- Two thermal vacuum performance tests planned (November 2018, February 2019)

- Current delivery to observatory integrator, late summer 2019

\section{TIRS-2 Optical Telescope System}

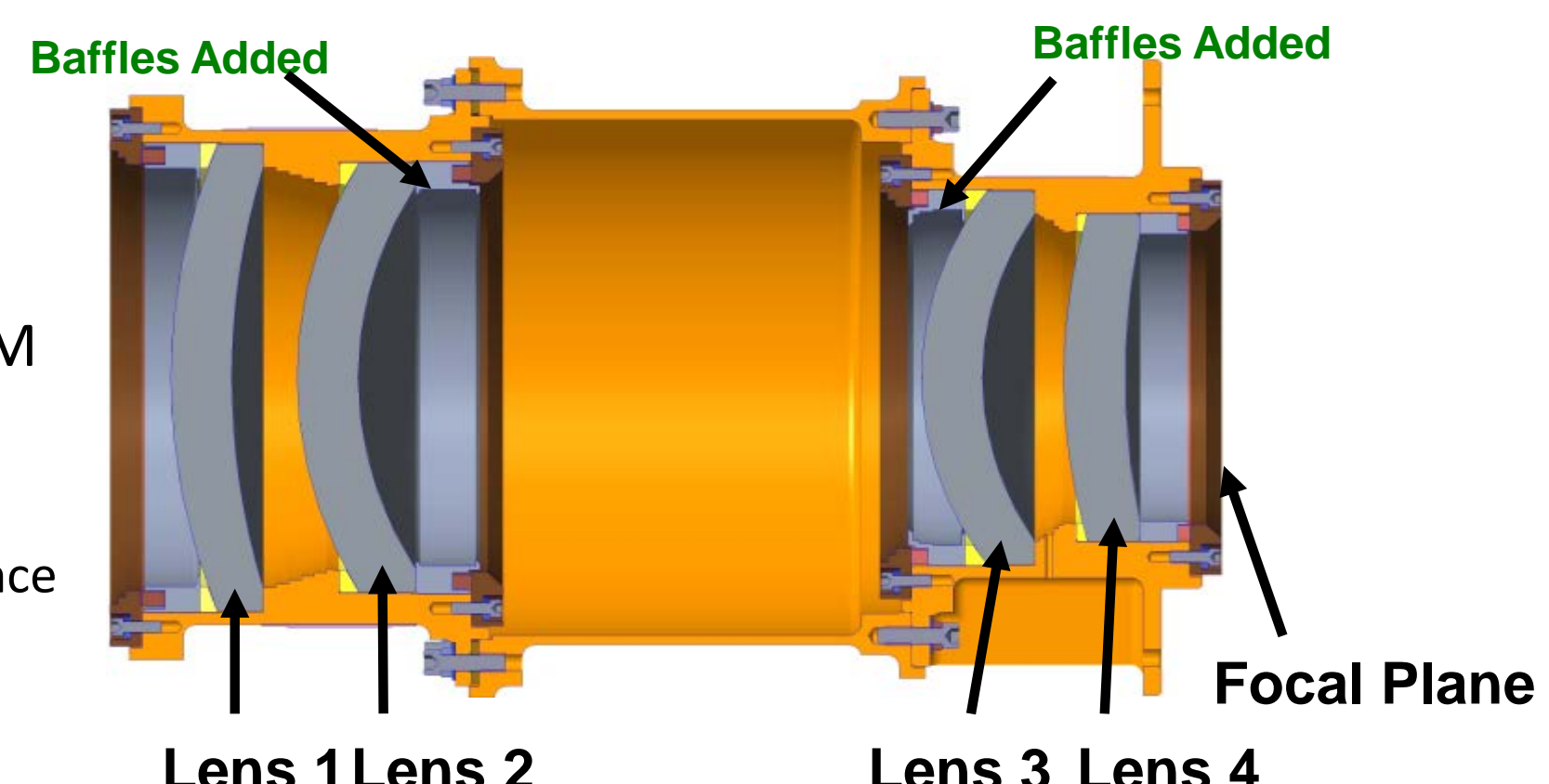

Lens 1 Lens 2

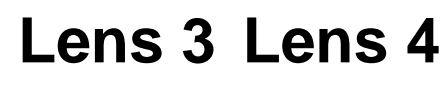




\section{Landsat-9 TIRS -2 Stray Light Performance (2)}

- Modeling and measurement indicated that primary source of stray light was lens 3 mounting structure ( $13^{\circ}$ feature)

- Models also showed affect from lens 2 mounting structure $\left(22^{\circ}\right.$ feature not originally seen on-orbit, but found later - weak)

- Added new baffles at both lens 2 and $3-$ models predicted $\sim 10 x$ reduction in stray light at $13^{\circ}$ off axis - measurements confirmed; smaller change (and original problem) at $22^{\circ}$

- New design should have comparable radiometric uncertainty to previous Landsat thermal radiometers, with possible exception of extreme background and target temperature differences $(>50 K)-I$ made this number up

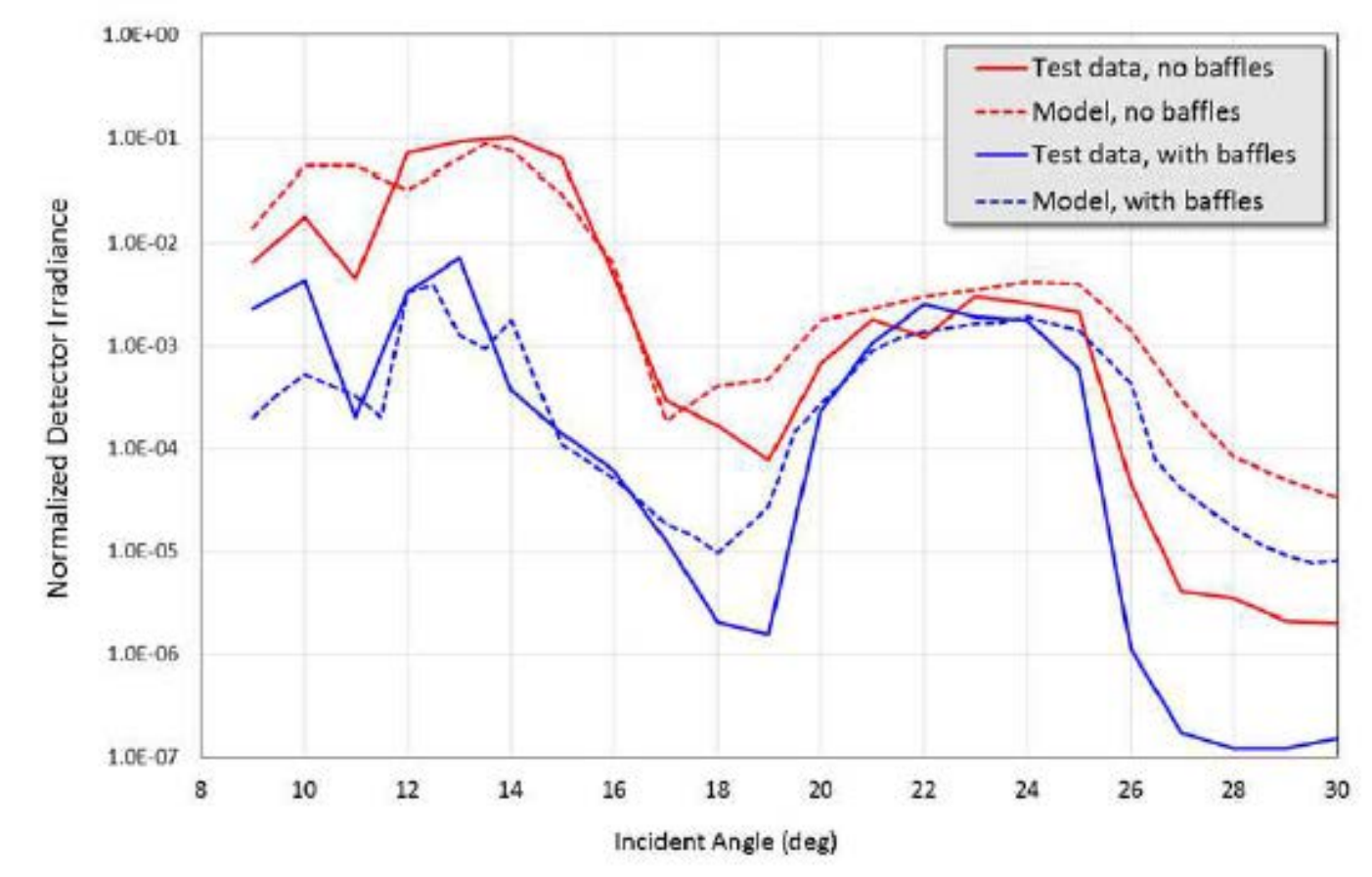




\section{Summary}

- The Landsat-8 TIRS and OLI sensors continue to operate well on-orbit.

- Both are very radiometrically stable. The TIRS stray light correction algorithm improves both absolute and relative radiometry of the data products.

- The Landsat-9 TIRS-2 and OLI-2 instruments have entered the integrated instrument test phase.

- Partially integrated instrument test results indicate that TIRS-2 and OLI-2 will have comparable noise, operability and stability behavior.

- Added baffles to the TIRS-2 design have reduced stray light by about an order of magnitude, which should allow comparable performance to historical Landsat-7 $\mathrm{ETM}+$ thermal data without algorithmic stray light correction.

- Expect Landsat-9 to launch in December 2020 at which point there will be two Landsat and two Sentinel-2 spacecraft on-orbit, providing high quality multispectral data every few days on average. 